\title{
Void Content in Out-of-Autoclave Manufacturing Processes
}

\author{
Cecilia L. Wilson ${ }^{1}$, Ethan Currens ${ }^{1}$ and Joseph F. Rakow ${ }^{1}$ \\ ${ }^{1 .}$ Exponent, Inc., Failure Analysis Associates, Menlo Park, USA.
}

Due to specific demands for composite parts in a variety of products such as automobiles, sporting goods, and civil infrastructure, product manufacturers have developed and implemented a number of out-of-autoclave (OOA) processes. These processes generally aim to achieve adequate compaction and cure while realizing efficient part turnaround. OOA processes include compression molding, vacuumbagging, resin infusion, filament winding, pultrusion, and resin transfer molding. These processes create composite components that contain some amount of voids. This paper, to be accompanied by a conference presentation, provides a brief survey of available information regarding void content generally associated with OOA processes.

A void in a composite laminate is defined by the ASM Handbook as "air or gas that has been trapped and cured into a laminate [1]. Porosity is an aggregation of microvoids." Examples of voids are shown in Figure 1. A metric commonly used to quantify the presence of voids is percent void content, also referred to as void fraction. Void content is defined in ASM Handbook as the volumetric percentage of trapped pockets of air or gas within a composite material [1]. Void content can be determined following standard ASTM D2734, as long as the densities of the resin, fiber, and cured composite are known. Alternatively, and in many cases preferably, void content can be determined using an image analysis approach.

Image analysis is a useful method to measure void content because it does not depend on a priori knowledge of fiber and matrix densities. A mounted cross-section of the laminate is imaged using an optical or electron microscope. The microscopic image is then post-processed so that fibers, matrix, and air can be distinguished by pixel color intensity distribution. Once these have been identified, the void pixel area is calculated, and void content computed for that area of interest. Figure 2 shows a scanning electron microscope image of a composite sample before and after image processing. The void content calculated for this particular image is $2.1 \%$.

A survey of void content data related to various OOA processes suggests that a range of approximately $2 \%$ to $4 \%$ void content is commonly produced. The present authors measured void content in bladder compression-molded carbon fiber reinforced polymer (CFRP) laminates in certain commercially available sporting goods, with a resulting void content in the range of $1.6 \%-3.6 \%$. Similarly, the authors of [2] reported void content of up to $3.4 \%$ for related processes. The present authors measured void content in glass fiber reinforced polymer (GFRP) composite laminates manufactured by vacuum assisted resin transfer molding (VARTM), identifying a void content range of $0.5 \%$ to $2.5 \%$. These results are consistent with the $2.15 \%$ void content established in [3]. CFRP laminates manufactured using an oven-vacuum bag process were reported in [4] to have $4 \%$ void content. Filament winding processes were found in one study to be within $3 \%$ void content [5].

The intended application of a product helps determine, in part, acceptable void content levels. Available literature suggests that some mechanical properties are more sensitive to void content than others, and in some cases the presence of voids up to a specified volume fraction can result in little to no effect on 
mechanical properties [2] [5] [6] [7]. The ASM Handbook states, "Because the end-use requirements of composites are so different, allowable void contents vary as well." Hence, the presence of voids alone is not always sufficient evidence to establish a product defect. Microscopic examination and engineering analysis often provide the necessary guidance for evaluating the effect of voids in a specific product and application.

References:

[1] ASM International, "ASM Handbook; Composites (Volume 21)," 2001, pp. 760,952,955,1135.

[2] J.P. Anderson and M.C. Altan, Journal of engineering materials and technology, October 2012.

[3] Youssef K. Hamidi, et al, Journal of engineering materials and technology, pp. 420-426, October 2004.

[4] "Composite Materials Hnadbook (CMH-17); Volume 2," SAE International.

[5] A. Brent Strong, Fundamentals of composites manufacturing; materials, methods and applications, Society of manufacturing engineers, 2008.

[6] Ling Liu, et al, Composites structures, vol. 73, pp. 303-309, 2006.

[7] A.R. Chambers, et al, International journal of fatigue, vol. 28, pp. 1389-1398, 2006.
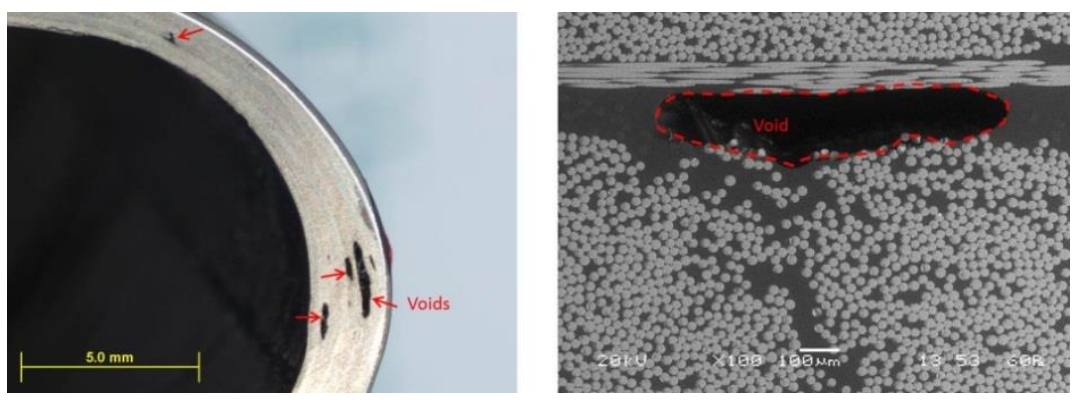

Figure 1. Examples of voids in a composite laminate. Left: stereo-microscope image of carbon fiber reinforced composite laminate (compression molded). Right: Scanning electron microscope image of glass fiber reinforced composite laminate (VARTM).
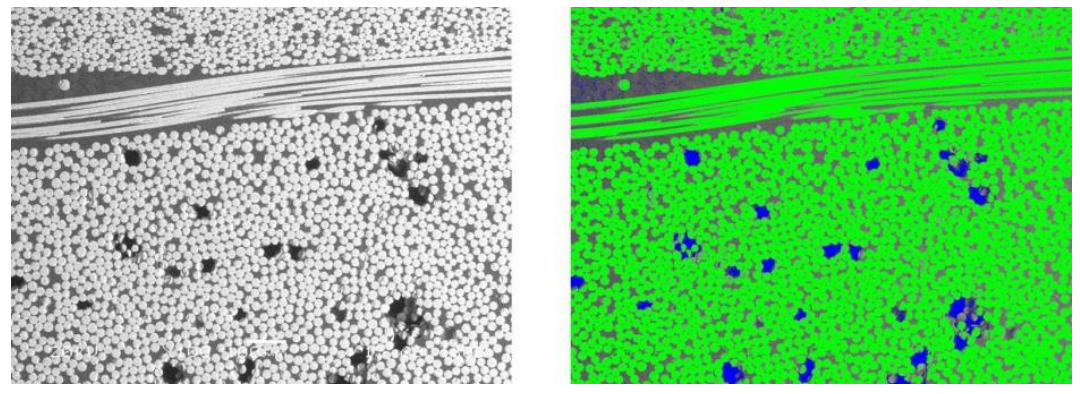

Figure 2. Example of microscopic image used to compute void content. The voids are identified by the blue pixels, the fibers by the green pixels and the matrix by the grey pixels. 